\title{
Microcirculatory effects of systemic metabolic correction with reactive oxygen species: An experimental study
}

\author{
Andrew K. Martusevich ${ }^{1,2, * \odot ~}{ }^{\circ}$ Konstantin A. Karuzin ${ }^{3}$, Levon R. Dilenyan ${ }^{1 \odot}$, Sergey P. Peretyagin ${ }^{4 \odot}$
}

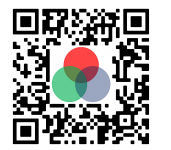

Use your smartphone to scan this QR code and download this article

\begin{abstract}
${ }^{1}$ Privolzhsky Research Medical
University, Nizhny Novgorod, Russia

${ }^{2}$ Nizhny Novgorod State Agricultural Academy, Nizhny Novgorod, Russia

${ }^{3}$ Bioniq Health-Tech Solutions Ltd., London, United Kingdom

${ }^{4}$ Association of Russian Ozone Therapeutists, Nizhny Novgorod, Russia
\end{abstract}

\section{Correspondence}

Andrew K. Martusevich, Privolzhsky Research Medical University, Nizhny Novgorod, Russia

Nizhny Novgorod State Agricultural Academy, Nizhny Novgorod, Russia

Email: cryst-mart@yandex.ru

\section{History}

- Received: Jul 21, 2020

- Accepted: Sep 18, 2020

- Published: Oct 04, 2020

DOI : 10.15419/bmrat.v7i10.636

\section{Check for updates}

\section{Copyright}

(C) Biomedpress. This is an openaccess article distributed under the terms of the Creative Commons Attribution 4.0 International license.

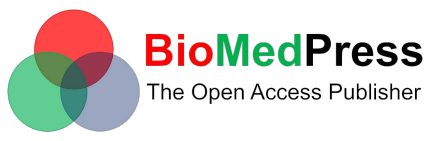

\begin{abstract}
Introduction: The purpose of this study is to estimate microcirculation changes under systemic (intraperitoneal) administration of ozonized saline. Methods: For this study, we formed four equal groups of Wistar male rats ( $n=10$ per group). Rats of first (control) group was intraperitoneally injected with non-ozonized sterile saline solution (daily administration volume $-1 \mathrm{ml}$.) during 30 days. Animals of other groups ( $n=10$ for second, third and fourth groups) received 30 intraperitoneal infusions ( $1 \mathrm{ml} /$ day) daily with ozonized saline solution (saturating ozone concentration for indicated groups - 3000, 10000 and $40000 \mathrm{mcg} / \mathrm{l}$, ozone dose per procedure - 0.75, 2.5 and 10 mcg, respectively). Technology of the Laser Doppler Flowmetry (LDF) along with "LAKK-02" device (Moscow, Russia) was used for complex estimation of skin microcirculation state. This technology allows us to study blood flow intensity in skin microvessels at the first and thirty-first days of the experiment. We also can estimate regulatory mechanisms of microcirculation support and the presence of shunt paths of the microcirculation. Results: We studied the dose-dependent response of microcirculation on ozone infusions in chronic experiments. We found that long-lasting course (30 procedures) of intraperitoneal administration of ozonized sodium chloride solution provides an increase in the level of microcirculation index compared to that of the control (injections of nonozonized saline solution), regardless of the applied dose of ozone. At the same time, the level of the microcirculation response was directly determined by the introduced amount of ozone, and we fixed non-linear dependence on it. Our study allowed us to show that only low doses of ozone $(0.75 \mathrm{mcg} /$ day) have proadaptive effects on the microcirculatory bed. This was shown both in the dynamics of the microcirculation index and the state of regulatory mechanisms. Middle ozone dose $(2.5 \mathrm{mcg} / \mathrm{day})$ also caused the stimulation of blood flow in small vessels, though this was predominantly through other mechanisms (neurogenic components). The most negative reaction of microcirculation was observed for high ozone dose $(8 \mathrm{mcg})$. Conclusion: Despite the activation of microcirculation observed in this case, we have identified that the mechanism was primarily through the respiratory component regulation and via formation of "steal syndrome" in the tissue. Key words: ozone, microcirculation, lipid peroxidation, antioxidant system, metabolic correction
\end{abstract}

\section{INTRODUCTION}

The sanogenic potential of ozone in gas phase and different ozonized solutions has been demonstrated in many clinical and experimental investigations ${ }^{1-3}$. It is proposed that the trigger mechanism of ozone biological action includes the influence of oxidative metabolism of blood and tissues with moderate stimulation of lipid peroxidation and predominant activation of the antioxidant system ${ }^{4-7}$. These effects initiate the complex of metabolic reaction, such as optimization of cell energy production, intensification of oxidative and enzyme detoxication, etc. ${ }^{1,5-12}$.

\section{MATERIALS - METHODS}

\section{Animals and exposures}

This study was performed on Wistar male rats (40 animals in total). Inclusion criteria for animals were body mass (200 - $250 \mathrm{~g})$, and absence of somatic and infection pathology. Male rats were used for exclusion of hormonal changes of blood flow parameters. The common design of our study is illustrated in Figure 1.

We formed four equal groups of rats $(n=10$ per group). Animals of the first (control) group $(n=10)$ were intraperitoneally injected with non-ozonized sterile saline solution (daily administration volume $-1 \mathrm{ml}$.) throughout 30 days. Animals of other groups (groups $2-4, \mathrm{n}=10$ per group) received 30 intraperitoneal infusions ( $1 \mathrm{ml} /$ day) with ozonized saline solution (saturating ozone concentration for indicated groups - 3000, 10,000 and 40,000 mcg/l, ozone dose per procedure $-0.75,2.5$ and $10 \mathrm{mcg}$, respectively $\left.{ }^{5,6}\right)$. Ozone and oxygen mixture was produced with "Medozons-System" ozonator (Nizhny Novgorod, Russia). 


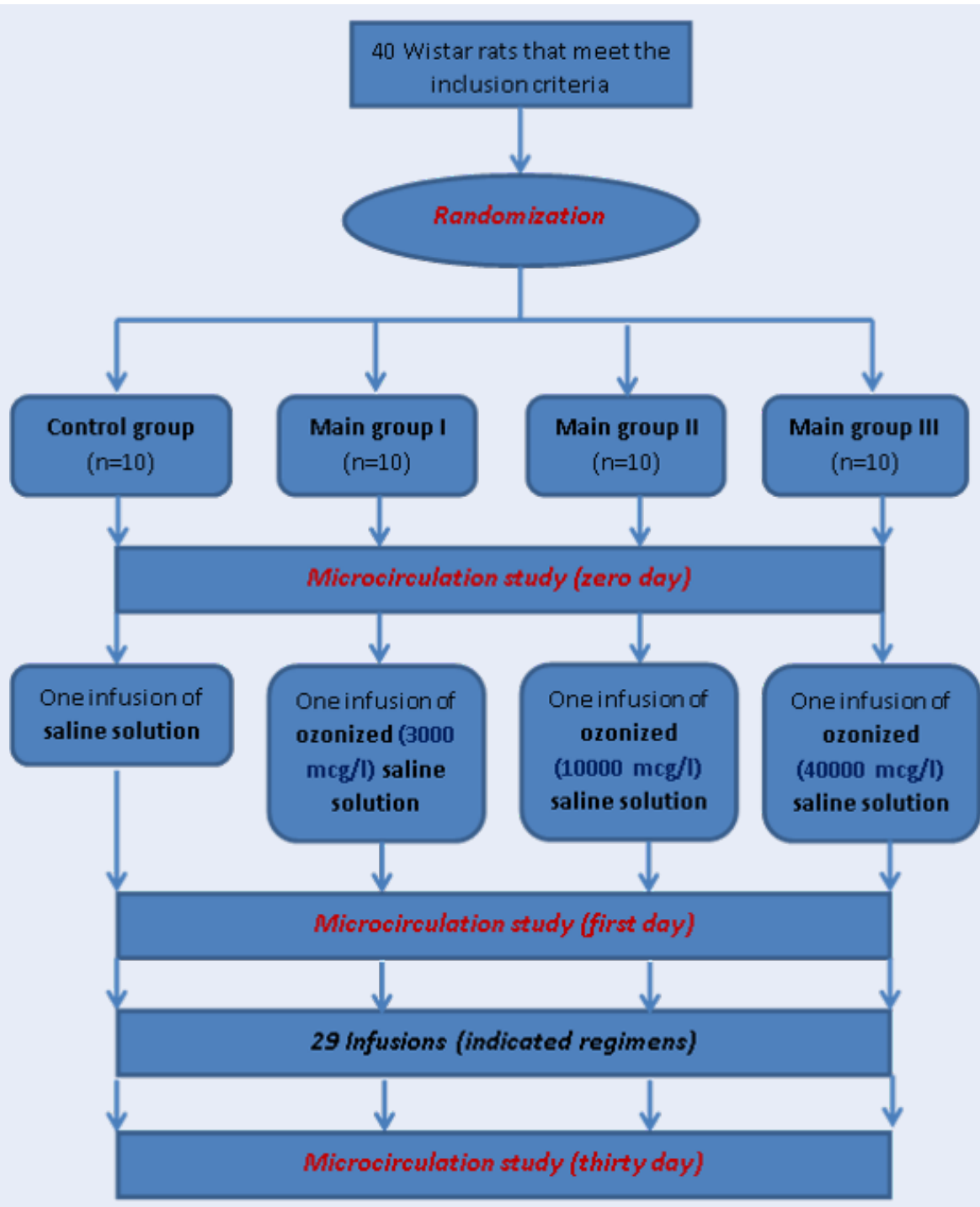

Figure 1: Study design.

\section{Microcirculation study}

Technology of the Laser Doppler flowmetry (LDF) with "LAKK-02" device (Moscow, Russia) was used for complex estimation of skin microcirculation state. In order to exclude the factor of motor activity of animals, the study of microcirculation was carried out under combined anesthesia (combination of Zoletil [1 $\mathrm{mg} / \mathrm{kg}]$ and Xylavet 50 [15 mg/kg]).

This technology allows us to study blood flow intensity in skin microvessels at days 0,1 , and 31 of the experiment. Intensity of local hemodynamics was estimated with microcirculatory index (MI), registering in perfusion units (perf. un.). Microcirculatory index is an integral indicator of blood flow intensity, calculated as an average value for 3 minutes. We also can estimate regulatory mechanisms of microcirculation support and the presence of shunt paths of the microcirculation. Amplitude and frequency analysis of LDF-grams allow studying main regulatory components of microcirculation, such as endothelial (NOdependent), neurogenic, myogenic, cardiac and respiratory ones. Role of bypasses in tissue perfusion was calculated with bypass coefficient (BC).

\section{Statistics}

The results were processed using the Statistica 6.0 program $^{13}$. All the data were processed with standard algorithms of descriptive statistics and were presented as Mean \pm SD. Student's t-test was used for detection of statistical differences. 


\section{RESULTS}

It was stated that on the second day after the start of the infusion course, we fixed stimulation of microcirculation intensity on 62,25 and $72 \%$ to the level of control group under the use of $3000,10,000$, and 40,000 mcg ozone/l, respectively ( $\mathrm{p}<0.05$ for all groups compared to control group). It is noteworthy that stimulation of blood flow through small vessels under the use of low ozone dose $(3000 \mathrm{mcg} / \mathrm{l})$ is predominantly supported by activation of endothelial mechanisms, and is associated with nitric oxide (NO) release.

Bypass coefficient was increased significantly after first ozone infusion under action of 3000 and 10000 $\mathrm{mcg} / \mathrm{l}$ (30 or $34 \%$, respectively, to the control value; $\mathrm{p}<0.05)$. This tendency indicated on initiation of adaptive mechanisms in these cases. Infusions of high ozone doses $(40000 \mathrm{mcg} / \mathrm{l})$ caused the clear decrease of bypass coefficient.

At the end of experiment (after 30-days of ozone infusions), the maximal elevation of the microcirculatory level was $88.3 \%$ relative to the control group (which receives infusions of non-ozonized saline; $\mathrm{p}<0.05)$. It was fixed only for minimal ozone concentration (3000 $\mathrm{mcg} / \mathrm{l}$ ). Other ozone doses also caused an intensification of blood stream in small vessels (Figure 2), but it was lesser to low ozone concentration (at 47.2 and $66.7 \%$, compared to control value; $\mathrm{p}<0.05$ for both groups). These data indicate a stimulating effect of systemic ozone therapy on microcirculation in chronic experiments, though the correlation with ozone dose is non-linear.

Analysis of regulatory mechanisms of microcirculation allows for showing its differences when used at high, medium and low ozone doses at the end of the experiments (Figure 3). Our investigations demonstrated that use of low ozone doses $(3000 \mathrm{mcg} / \mathrm{l})$ provoked a moderate elevation of endothelial, neurogenic, myogenic and cardiac components. This tendency is observed most clearly for neurogenic and myogenic regulatory components (increasing at 56.3 and $33.3 \%$, respectively, compared to control group; $\mathrm{p}<0.05)$. It should be noted that on day 31 of experiment, the prevalence of endothelial regulation was observed after the first procedure of ozone infusion was replaced by other internal mechanisms (respiratory and cardiac components).

Medium ozone doses induced the activation only of the neurogenic component of regulation, with minimal increase of external mechanisms (respiratory). At that time, endothelial components saved on control values, and the myogenic one was moderately decreased $(18.5 \%$ compared to the control group; $\mathrm{p}<$
$0.05)$.

On the contrary, prolonged infusions of saline at high ozone concentration $(40000 \mathrm{mcg} / \mathrm{l})$ caused disadaptive changes of regulatory mechanisms (Figure 4). It included depression of all regulatory components, except respiratory ones. Inhibition of activity of the components was particularly evident for internal ("intravascular") mechanisms, mostly for myogenic components (decreasing at $42.6 \%$ compared to control level; $\mathrm{p}<0.01)$.

Estimation of the bypass state after the ozone infusion course demonstrated that use of low ozone dose $(0.75$ $\mathrm{mcg} /$ day) caused only moderate increase of bypass coefficient, but injections of middle $(2.5 \mathrm{mcg} / \mathrm{day})$ or high (10 mcg/day) of ozone led to a marked elevation of this parameter (Figure 5). It is known that the marked increase in the value of this index indicates a decline in nutritive blood flow (microcirculation) and a formation of "steal syndrome". The given nature of the reaction of shunt paths of microvasculature confirms dis-adaptive shifts due to long-lasting (30 days) introduction of ozonized physiological solution at a high ozone dose $(8 \mathrm{mcg} /$ day $)$ to the animals.

\section{DISCUSSION}

Our study demonstrated a dose-dependent response of microcirculation on ozone infusions in chronic experiments. We stated that a long-lasting course (30 procedures) of intraperitoneal administration of ozonized sodium chloride solution provides an increase in the level of microcirculation index compared to that of control (which received only injections of non-ozonized saline solution), regardless of the applied dose of ozone. At the same time, the severity of the microcirculation response was directly determined by the amount of ozone introduced, and we fixed non-linear dependence on it. This confirms the non-linear nature of the metabolic shifts that we obtained for these concentrations in previous studies ${ }^{5,6}$. Evaluating the integrative indicator of microcirculation state (microcirculation index), it should be noted that the most pronounced stimulating effect was established for the minimum concentration of ozone $(3000 \mathrm{mcg} / \mathrm{l})$. This is provided by increasing the role of internal factors of regulation (endothelial, neurogenic, and myogenic), while maintaining the initial level of external components (respiratory and cardiac). At the same time, the bypass rate increases moderately, remaining proportional to the microcirculation index. The nature of these shifts suggests an adaptive response to this ozone dose (Figure 4).

Middle ozone dose $(2.5 \mathrm{mcg} /$ day $)$ also caused the stimulation of blood flow in small vessels, but its effects are predominantly through other mechanisms 


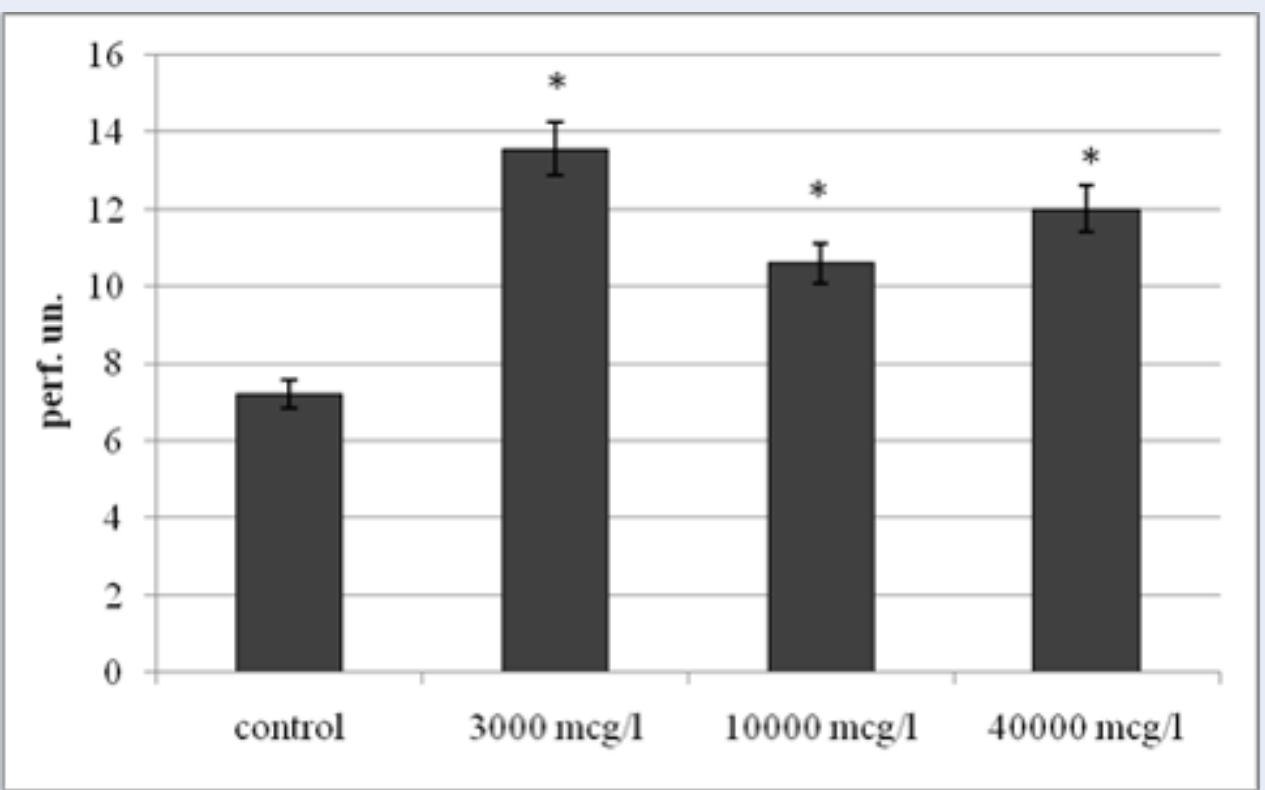

Figure 2: Microcirculatory index in the end of subchronic experiment for 30-days systemic infusions of ozonated salin. Figure illustrates the level of parameter in control group (without any manipulations) and in main groups, which get intraperitoneal injections of ozonized saline of ozone concentrations 3000, 10000 and $40000 \mathrm{mcg} / \mathrm{l}$, respectively ("*" -level of statistical differences to control level $p<0.05$ ).

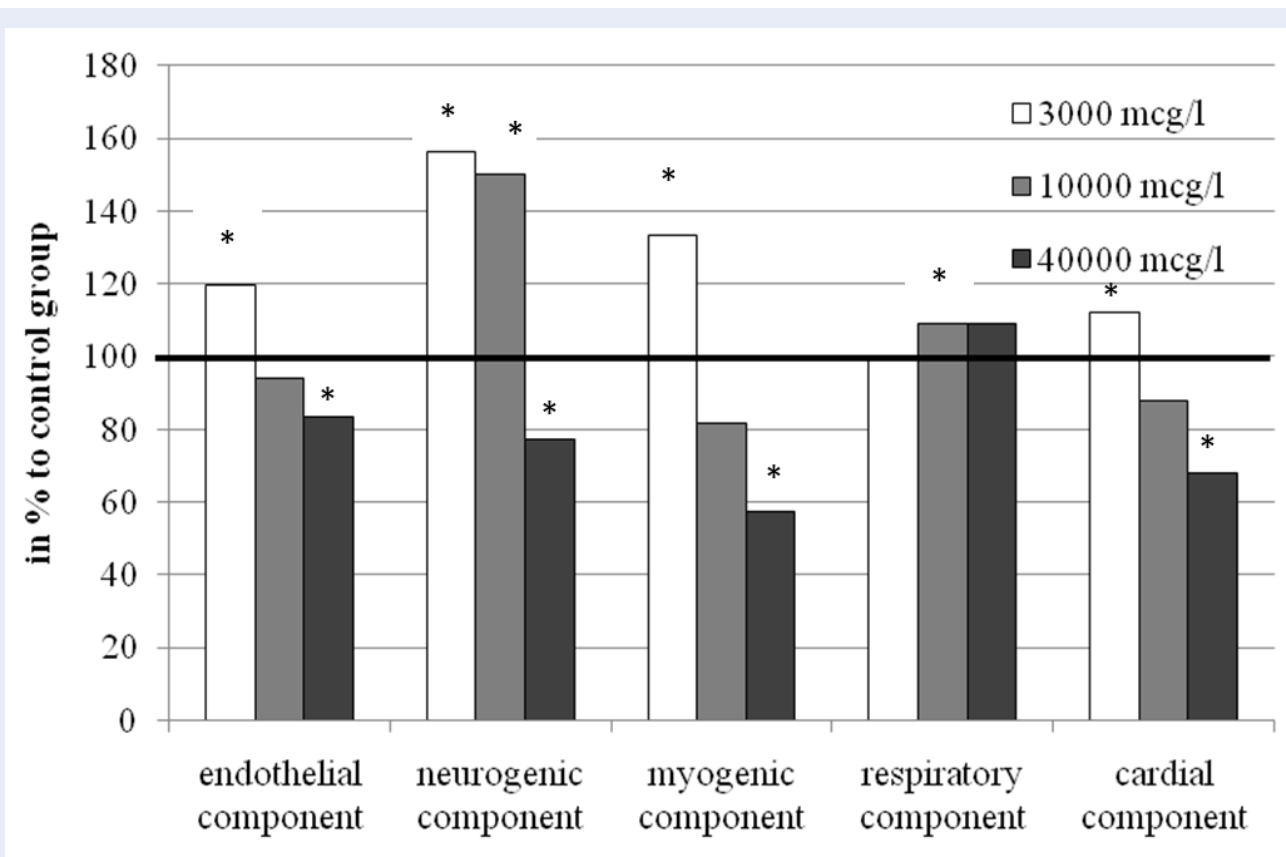

Figure 3: Microcirculatory index in the end of subchronic experiment for 30-days systemic infusions of ozonated salin. Figure illustrates the level of parameter in control group (without any manipulations) and in main groups, which get intraperitoneal injections of ozonized saline of ozone concentrations 3000, 10000 and $40000 \mathrm{mcg} / \mathrm{l}$, respectively ("*" - level of statistical differences to control level $p<0.05$ ) 


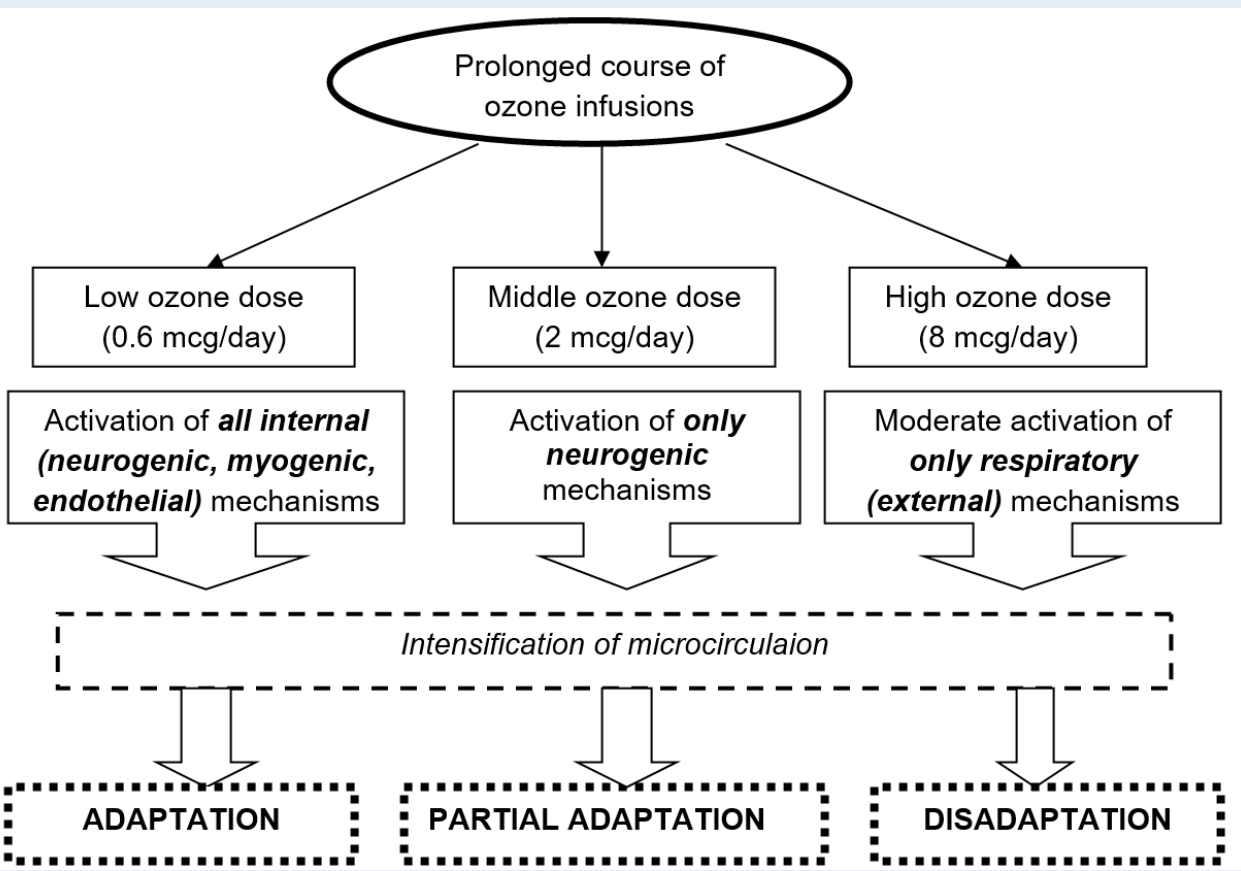

Figure 4: Variants of microcirculation response to use of different ozone doses $(0.6,2$ and $8 \mathrm{mcg} / \mathrm{day})$ in chronic experiment.

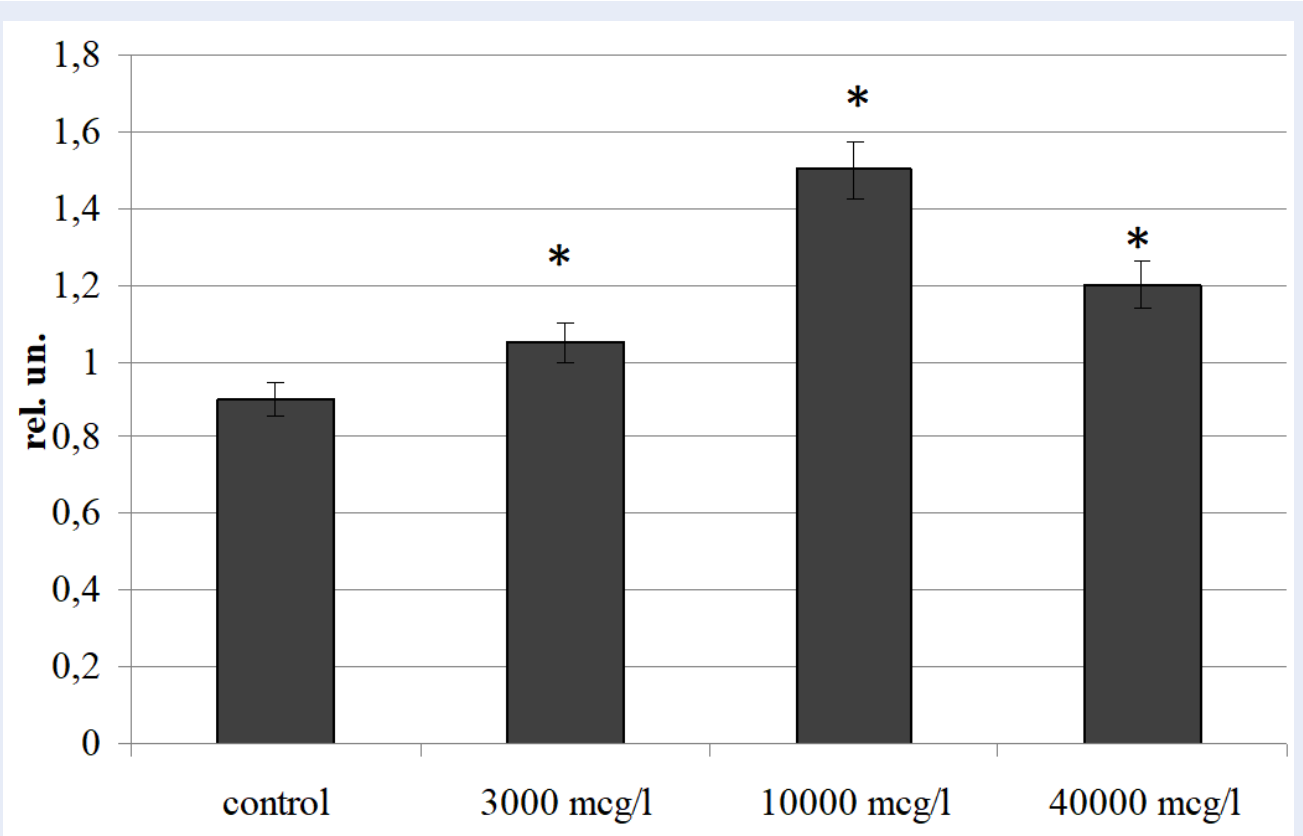

Figure 5: Level of bypass coefficient in the end of subchronic experiment for 30-days systemic infusions of ozonated saline. Figure illustrates the level of parameter in control group (without any manipulations) and in main groups, which get intraperitoneal injections of ozonized saline of ozone concentrations 3000, 10000 and $40000 \mathrm{mcg} / \mathrm{l}$, respectively ("**" - level of statistical differences to control level $p<0.05$ ). 
(neurogenic components). This indicates a partial adaptation of the microcirculatory bed to the intraperitoneal administration of this amount of ozone. The most negative (disadaptive) response of microcirculation was observed for high ozone dose $(10 \mathrm{mcg})$. Despite the fact that activation of microcirculation was observed in this case, we have identified that the effects work primarily through the respiratory component of the regulation, and results in the formation of "steal syndrome" in the tissue.

\section{CONCLUSION}

Our study enabled us to show that only low doses of ozone $(0.75 \mathrm{mcg})$ have proadaptive effects on the microcirculatory bed. This is shown both in the dynamics of the microcirculation index and the state of regulatory mechanisms. On the contrary, intraperitoneal administration of a solution of sodium chloride containing a high concentration of ozone $(40,000$ $\mathrm{mcg} / \mathrm{l})$ contributes to the inhibition of microcirculation, which indirectly indicates the presence of signs of subchronic toxicity in this agent.

\section{ABBREVIATIONS}

perf. un.: perfusion units

rel. un.: relative units

mcg: microgram

\section{AUTHOR'S CONTRIBUTIONS}

A.K.M., L.R.D. and S.P.P. contributed to the conceptualization and design of the study, the analysis and interpretation of data. A.K.M., L.R.D. and K.A.K. produced all experiments. They were drafting the article and revising the article critically for important intellectual content. All authors read and approved the final manuscript.

\section{FUNDING}

This article had no financial support of this faculty.

\section{AVAILABILITY OF DATA AND MATERIALS}

Data and materials used and/or analyzed during the current study are available from the corresponding author on reasonable request.

\section{ETHICS APPROVAL}

The study was approved by Local Ethic Committee of Privolzhsky Research Medical University (no. 3/18 from 05/02/2018).

\section{CONSENT FOR PUBLICATION}

The authors hereby consents that the Publisher publishes the Work.'

\section{COMPETING INTERESTS}

The authors declare that they have no competing interests.

\section{REFERENCES}

1. Aydos TR, Başar MM, Kul O, et al. Effects of ozone therapy and taurine on ischemia/reperfusion-induced testicular injury in a rat testicular torsion model. Turk J Med Sci. 2014;44(5):749755. PMID: 25539540. Available from: https://doi.org/10.3906/ sag-1308-20.

2. Bartz RR, Piantadosi CA. Clinical review: oxygen as a signaling molecule. Crit Care. 2010;14(5):234. PMID: 21062512. Available from: https://doi.org/10.1186/cc9185.

3. Bocci V, Zanardi I, Travagli V. Has oxygen-ozonetherapy a future in medicine? . Rev Esp Ozonother. 2010;1:33-39. Available from: https://doi.org/10.5455/jeim.161210.ir.002.

4. Griendling KK, FitzGerald GA. Oxidative stress and cardiovascular injury. Part I: basic mechanisms and in vivo monitoring of ROS. Circulation. 2003;21:1912-1916. PMID: 14568884. Available from: https://doi.org/10.1161/01.CIR.0000093660.86242. BB.

5. Martusevich AK., Soloveva AG, Peretyagin SP, Didenko NV. Estimation of different ozone doses action on rat liver oxidoreductases state. Int J Ozone Ther. 2013;12(2):179-181.

6. Peretyagin SP, Martusevich AK, Solovyeva AG et al. Enzymological evaluation of hepatotropic effect of ozone in a subchronic experiment. Bulletin of Experimental Biology and Medicine. 2013;154(6):789-791. PMID: 23658925. Available from: https://doi.org/10.1007/s10517-013-2057-9.

7. Wang L, Chen H, Liu XH et al. Ozone oxidative preconditioning inhibits renal fibrosis induced by ischemia and reperfusion injury in rats. Exp Ther Med. 2014;8(6):1764-1768. PMID: 25371729. Available from: https://doi.org/10.3892/etm.2014 2004.

8. Nogales CG, Ferrari PH, Kantorovich E., Lage-Marques JL. Ozone therapy in medicine and dentistry. J Contemp Dent Pract. 2008;9(4):75-84. PMID: 18473030. Available from: https: //doi.org/10.5005/jcdp-9-4-75.

9. Bocci V, Zanardi I, Huijberts MS, Travagli V. It is time to integrate conventional therapy by ozone therapy in type- 2 diabetes patients. Ann Transl Med. 2014;2(12):117.

10. Domb WC. Ozone therapy in dentistry. A brief review for physicians. Interv Neuroradiol. 2014;20(5):632-636. PMID: 25363268. Available from: https://doi.org/10.15274/INR2014-10083.

11. Magalhaes FN, Dotta L, Sasse A et al. Ozone therapy as a treatment for low back pain secondary to herniated disc: a systematic review and meta-analysis of randomized controlled trials. Pain Physician. 2012;15(2):E115-E29.

12. Zaky S, Kamel SE, Hassan MS et al. Preliminary results of ozone therapy as a possible treatment for patients with chronic hepatitis C. J Altern Complement Med. 2011;17(3):259-263. PMID: 21417811. Available from: https://doi.org/10.1089/acm.2010. 0016.

13. Gubler EV, Genkin AA. Application of nonparametric statistical criteria in biomedical research. Saint-Petersburg. 2003;p. 141. 